\title{
O Museu da Diversidade Sexual como ecologia informacional complexa: um estudo sob a ótica da encontrabilidade da informação e arquitetura da informação pervasiva
}

\author{
Jean Fernandes Brito \\ Universidade Estadual Paulista, Faculdade de Filosofia e Ciências, Departamento de Ciência da \\ Informação, Marília, SP, Brasil \\ jieanfernandes@gmail.com \\ Daniel Martinez-Ávila \\ Universidade Carlos III, Madrid, Espanha \\ martinez.avila@unesp.br
}

Fernando Luiz Vechiato Universidade Federal do Rio Grande do Norte, Departamento de Ciência da Informação, Natal, RN, Brasil vechiatto@gmail.com

Silvana Aparecida Borsetti Gregorio Vidotti Universidade Estadual Paulista, Faculdade de Filosofia e Ciências, Departamento de Ciência da Informação, Marília, SP, Brasil ssvidotti@unesp.br

DOI: https://doi.org/10.26512/rici.v13.n3.27647

Recebido/Recibido/Received: 2019-10-17

Aceitado/Aceptado/Accepted: 2020-08-05

Resumo: Considerando a importância em compreender o Museu da Diversidade Sexual da cidade de São Paulo como ecologia informacional complexa, tendo em vista que é composto por seus ambientes informacionais analógico e digital, esta pesquisa objetiva avaliá-lo a partir dos atributos da Encontrabilidade da Informação e da Arquitetura da Informação Pervasiva por meio de um checklist e a partir da técnica de observação participativa. De um modo geral, o Museu da Diversidade Sexual apresentou em sua grande maioria uma parcialidade no que diz respeito aos atributos de Encontrabilidade da informação e Arquitetura da Informação Pervasiva. Por se tratar de uma ecologia informacional complexa ele apresenta uma diversidade dos fatores envolvidos. Percebemos que os maiores problemas encontrados se referem às descobertas de informação e a mediação dos sujeitos informacionais e a ausência de elementos de acessibilidade no website os quais possibilitariam ampliar o acesso à informação por pessoas com deficiência. Por meio deste estudo foi possível potencializar as divulgações de ideias considerando os sujeitos informacionais no processo de produção e organização da informação, tornando o ambiente informacional digital, especialmente, mais colaborativo e interativo. Palavras-Chave: Ecologias Informacionais Complexas. Encontrabilidade da Informação. Arquitetura da Informação Pervasiva. Museu da Diversidade Sexual.

The Museum of Sexual Diversity as a complex information ecology: a study of its findability and pervasive information architecture

Abstract: Considering the importance of understanding the Museum of Sexual Diversity of the city of São Paulo as a complex information ecology, and provided that it is composed of its analog and digital 
information environments, this paper aims to evaluate the museum based on the attributes of findability and pervasive information architecture using a checklist and a participatory observation. In general, the Museum of Sexual Diversity presents, in its great majority, a partiality regarding the attributes of findability of information. Because it is a complex information ecology, it presents a diversity of factors involved. We noticed that the major problems that we found relate to the topics of information discovery and the mediation of information subjects; and the lack of elements of accessibility on the website which would make it possible to expand the access to information for people with disabilities. Through this study it was possible to enhance the dissemination of ideas related to the information subjects in the process of production and organization of information, making the digital informational environment more collaborative and interactive.

Keywords: Complex information ecologies. Findability of information. Pervasive architecture of information. Museum of Sexual Diversity.

El Museo de la Diversidad Sexual como ecología informacional compleja: un estudio sobre la óptica de la encontrabilidad de la información y la arquitectura de la información pervasiva

Resumen: Considerando la importancia de comprender el Museo de la Diversidad Sexual de la ciudad de São Paulo como una ecología informacional compleja, y teniendo en cuenta que se compone de los ambientes de información analógico y digital, esta investigación busca evaluarlo a partir de los atributos de encontrabilidad de la información y arquitectura de la información pervasiva por medio de un checklist y una observación participativa. En líneas generales, el Museo de la Diversidad Sexual presentó, en su gran mayoría, una parcialidad con respecto a los atributos de encontrabilidad de la información. Debido a que es una ecología informativa compleja, el museo presenta una diversidad de factores involucrados. Se comprobó que los principales problemas encontrados se relacionan con los descubrimientos de información y la mediación de temas informativos, así como la falta de elementos de accesibilidad web que permitirían ampliar el acceso a la información para personas con discapacidad. A través de este estudio fue posible mejorar la difusión de ideas considerando los temas informativos en el proceso de producción y organización de la información, haciendo específicamente que el entorno informativo digital sea más colaborativo e interactivo.

Palabras Clave: Ecologías Informacionales Complejas. Encontrabilidad de la Información. Arquitectura de la Información Pervasiva. Museo de la Diversidad Sexual.

\section{Introdução}

"As formas de organizar, representar e preservar a memória da humanidade, por meio de objetos museológicos e informações registradas, influencia a trajetória e o fortalecimento das pesquisas no contexto da Ciência da Informação" (FERREIRA; VIDOTTI, 2016, p.80).

No que diz respeito à preservação da memória, destacamos as manifestações culturais representadas materialmente das comunidades Lésbicas, Gays, Bissexuais, Transexuais e Travestis e Queer (LGBTTQ+), uma população ativa em sociedade que utiliza as Tecnologias de Informação e Comunicação (TIC), como forma de ampliação e manifestação social.

No entanto, "há poucas exposições em museus que tratam especificamente da sexualidade humana e que dão atenção aos temas ligados aos indivíduos ou aos grupos LGBTQ" (PINTO, 2012, p. 44). Isso se justifica ao fato de que muitas vezes as suas práticas sexuais são vistas com olhares preconceituosos e distantes das normas sociais impostas pela sociedade, (PINTO, 2012). 
Brito e Matias (2018) analisaram sob a ótica da encontrabilidade da Informação a página o Museu da Diversidade Sexual e investigaram alguns problemas no que diz respeito à navegação e busca no website.

Nesse sentido, o objeto de estudo deste artigo é o Museu da Diversidade Sexual (MDS) da cidade de São Paulo, uma ecologia informacional complexa, composta por seus ambientes informacionais analógico e digital, que tem como missão divulgar o patrimônio histórico e cultural da comunidade LGBTQ brasileira, em especial a paulista, valorizando a importância da diversidade sexual na construção social (MUSEU DA DIVERSIDADE SEXUAL, 2019).

Brandt, Vechiato e Vidotti $(2018$, p. 46) comentam que “[...] uma ecologia informacional complexa compreende os ambientes inseridos em um sistema que podem ser analógicos, digitais ou híbridos, conforme os suportes que estão inseridos".

Desse modo, esta pesquisa objetiva avaliar a ecologia informacional complexa do MDS, por meio do instrumento de avaliação proposto por Vechiato, Oliveira e Vidotti (2016), que contempla atributos da Encontrabilidade da Informação e da Arquitetura da Informação Pervasiva.

As questões de gênero e sexualidade que hoje são discutida em meios científicos de forma ampla e aceita, por muito tempo ficaram à margem não só das discussões de área, mas da própria realidade profissional. Com isso, para a Biblioteconomia que, historicamente, foi tão atrelada ao tecnicismo e as abordagens positivistas, pensar em públicos com necessidades específicas de informação, e tradicionalmente marginalizados, é um desafio, ainda nos dias de hoje. Além disso, justifica a relevância dessa pesquisa por ser o primeiro e único museu da América Latina que discute e expõe questões ligadas a gênero, sexualidade e a diversidade sexual.

Para melhor entendimento essa pesquisa aborda as discussões teóricas sobre Gênero, Sexualidade e Diversidade Sexual, Encontrabilidade da Informação e Arquitetura da Informação Pervasiva, com enfoque nas ecologias informacionais complexas e na Encontrabilidade da Informação em ambientes informacionais LGBTQ. Enfoca, ainda, o Museu da Diversidade Sexual enquanto ecologia informacional complexa, os aspectos metodológicos, as discussões e os resultados e, por fim, apresentam-se as considerações finais do estudo em questão.

\section{Gênero, sexualidade e diversidade sexual}

A necessidade de distinguir o relacionamento entre pessoas do mesmo sexo e do sexo oposto levou à introdução, por meio de um escritor húngaro (Károly Mária Kertbeny) no ano de 1869 , do termo homossexualidade para distinguir da heterossexualidade no que diz respeito ao impulso sexual ao qual a pessoa se orienta. Os termos homossexual ("homosexual") e 
homossexualidade ("homosexuality") foram usados por primeira vez em revistas médicas dos Estados Unidos nos anos 1890s, e, já em publicações generalistas nos anos 1920s (ALYSON PUBLICATION, 1989; GREENBLATT, 1990)

Pompeu e Souza $(2018$, p. 3) afirmam que: "As pessoas homossexuais são estigmatizadas em nossa sociedade e tratadas como inferiores, exatamente por não seguirem o padrão heterossexual de comportamento imposto". Já o termo homossexual denota uma vinculação ao discurso médico e asséptico, quase patológico, que significava o desvio da normalidade e do padrão. Por exemplo, foi no ano de 1974 que a American Psychiatric Association determinou que a homossexualidade não fosse uma patologia (DE LA TIERRA, 2008). $\mathrm{Na}$ fala comum do inglês, o termo gay (cuja origem significa e denota felicidade/feliz e foi utilizado por primeira vez nos Estados Unidos na década de 1930s) é preferido sobre o termo homossexual (homosexual em inglês) que é considerado de forma negativa como um termo "clinico, objetivador sexualmente e limitante" (GREENBLATT, 1990, p.80).

Além disso, é necessário, primeiramente, entender as diferenças entre gênero, sexo e orientação sexual. Sexo é um aspecto biológico da identidade sexual e é determinado pelas características físicas que diferenciam homens e mulheres. Orientação sexual é o aspecto relativo à atração sexual e afetiva em relação a outras pessoas. E identidade de Gênero, no conceito de identidade do indivíduo, é um conceito histórico e cultural, e trata-se de uma construção social, que compreende a escolha do indivíduo em relação a como ele se sente (NUNAN, 2003). Ellen Greenblatt sumariza a relação entre sexo biológico e identidade de gênero dizendo que "o sexo está entre as pernas, enquanto o gênero está entre as orelhas" (GREENBLATT 2011, p. 221).

Por outro lado, enquanto o sexo pode estar mais determinado de forma inata nas pessoas, os aspetos relacionados com a identidade de gênero e a orientação sexual são mais claramente construídos socialmente. Inclusive no caso do sexo biológico, existem casos como as pessoas intersexuais em que o sexo também precisa ser decidido, e essa escolha não estão isenta de pressões sociais e violência civil e institucional (GARCIA GUTIÉRREZ, 2014, p.396).

Enfim, conforme apontado por Ottonicar et al. (2019) a construção social das pessoas LGBTQ se dá por meio de suas demandas e criam um campo político de força social na sociedade civil, envolvendo TIC, sendo que suas ações se estruturam a partir de repertórios criados sobre temas e problemas em situações de conflitos, litígios e disputas.

\section{Encontrabilidade da Informação e Arquitetura da Informação Pervasiva}


O termo Findability foi apresentado por Peter Morville no ano de 2005 em seu livro Ambiente Findability e a tradução para a língua portuguesa não é consensual entre os autores. Sob essa perspectiva Vechiato $(2013$, p. 168) apresenta em sua tese de doutorado o conceito operatório de Encontrabilidade da informação e a define como:

Um elemento que se situa entre as funcionalidades de um ambiente informacional tradicional, digital ou híbrido e as características dos sujeitos, e deriva da mediação infocomunicacional.

Na prática, a ausência de uma Encontrabilidade da Informação efetiva é um dos problemas da Arquitetura da Informação na web, tendo em vista os pensamentos e ações divergentes da própria equipe que compõe o desenvolvimento de websites, como arquitetos da informação, designers, engenheiros e especialistas em marketing, tornando-se necessária a colaboração interfuncional e colaborativa (MORVILLE, 2005).

Sobre das funcionalidades dos ambientes informacionais, Vechiato, Oliveira e Vidotti (2016) apresentam atributos de Encontrabilidade da Informação e de Arquitetura da Informação Pervasiva que perpassam a produção, a organização, a disseminação e o (re)uso da informação e que são incorporados nos estudos das ecologias informacionais complexas, quais sejam: a) taxonomias navegacionais; b) instrumentos de controle terminológicos; c) folksonomias; d) metadados; e) mediação dos informáticos; f) affordances; g) wayfinding; h) descoberta de informação; i) acessibilidade e usabilidade; j) mediação dos profissionais da informação; k) mediação dos sujeitos informacionais; I) intencionalidade; $\mathrm{m}$ ) mobilidade, convergência e ubiquidade. No quadro 1, a seguir, são apresentados esses termos e atributos.

Quadro 1: Atributos da Encontrabilidade da Informação e Arquitetura da Informação pervasiva

\begin{tabular}{|c|l|}
\hline Atributo & \multicolumn{1}{c|}{ Descrição } \\
\hline $\begin{array}{c}\text { Taxonomias } \\
\text { navegacionai } \\
\text { s }\end{array}$ & $\begin{array}{l}\text { Utilizadas em estruturas de organização top-down, se referem à organização das } \\
\text { categorias informacionais com vistas a facilitar a navegação e a descoberta de } \\
\text { informações. Essas categorias, por exemplo, são organizadas geralmente em } \\
\text { menus ou no corpo das páginas Web, nas comunidades e coleções de repositórios } \\
\text { ou nas legendas utilizadas para descrição dos assuntos nas estantes das } \\
\text { bibliotecas, organizadas previamente a partir de um sistema de classificação. }\end{array}$ \\
\hline $\begin{array}{c}\text { Instrumentos de } \\
\text { controle } \\
\text { terminológico }\end{array}$ & $\begin{array}{l}\text { Compreendem os vocabulários controlados, como os tesauros e as ontologias, } \\
\text { para apoiar a representação dos recursos informacionais. }\end{array}$ \\
\hline
\end{tabular}




\begin{tabular}{|c|c|}
\hline Atributo & Descrição \\
\hline Folksonomias & $\begin{array}{l}\text { Estão relacionadas à organização social da informação e propiciam ao sujeito a } \\
\text { classificação de recursos informacionais, bem como encontrar a informação por } \\
\text { meio da navegação (uma nuvem de tags, por exemplo) ou dos mecanismos de } \\
\text { busca, ampliando as possibilidades de acesso. São utilizadas em estruturas de } \\
\text { organização bottom-up. Quando associadas aos vocabulários controlados e às } \\
\text { tecnologias semânticas, potencializam as possibilidades de encontrabilidade da } \\
\text { informação. }\end{array}$ \\
\hline Metadados & $\begin{array}{l}\text { Compreendem a representação dos recursos informacionais e são armazenados } \\
\text { em banco de dados para fins de recuperação da informação. }\end{array}$ \\
\hline $\begin{array}{l}\text { Mediação } \\
\text { dos } \\
\text { informáticos }\end{array}$ & $\begin{array}{l}\text { Está associada ao desenvolvimento de sistemas, dispositivos, bancos de dados e } \\
\text { interfaces com utilização de linguagens computacionais, com vistas à gestão e à } \\
\text { recuperação da informação. }\end{array}$ \\
\hline $\begin{array}{l}\text { Mediação dos } \\
\text { profissionais } \\
\text { da informação }\end{array}$ & $\begin{array}{l}\text { Ocorre em ambientes informacionais em que há sujeitos institucionais } \\
\text { envolvidos na seleção, estruturação e disseminação da informação. }\end{array}$ \\
\hline $\begin{array}{l}\text { Mediação dos } \\
\text { sujeitos } \\
\text { informacionais }\end{array}$ & $\begin{array}{l}\text { Está relacionada às aç̃̃es infocomunicacionais que os sujeitos informacionais } \\
\text { empreendem em quaisquer sistemas e ambientes informacionais, por exemplo, } \\
\text { no que diz respeito à produção e à organização da informação e do conhecimento } \\
\text { em ambientes colaborativos, gerados a partir de seus conhecimentos, } \\
\text { comportamento e competências que caracterizam sua Intencionalidade. }\end{array}$ \\
\hline Affordances & $\begin{array}{l}\text { Funcionam como incentivos e pistas que os objetos possuem e proporcionam aos } \\
\text { sujeitos a realização de determinadas ações na interface do ambiente. Essas ações } \\
\text { estão relacionadas à orientação, localização, encontrabilidade, acesso, } \\
\text { descoberta de informações entre outras. }\end{array}$ \\
\hline Wayfinding & $\begin{array}{l}\text { Associado a orientação espacial, utilizando-se de aspectos que facilitem a } \\
\text { localização, a encontrabilidade e a descoberta de informações por meio da } \\
\text { navegação na interface do ambiente. }\end{array}$ \\
\hline $\begin{array}{l}\text { Descoberta } \\
\text { de } \\
\text { informações }\end{array}$ & $\begin{array}{l}\text { Está condicionada aos demais atributos de encontrabilidade da informação no } \\
\text { que diz respeito às facilidades que a interface (navegação e/ou mecanismos de } \\
\text { busca) oferece para encontrar a informação adequada às necessidades } \\
\text { informacionais do sujeito, bem como a possíveis necessidades informacionais de } \\
\text { segundo plano. }\end{array}$ \\
\hline $\begin{array}{l}\text { Acessibilidade } \\
\text { e Usabilidade }\end{array}$ & $\begin{array}{l}\text { Relacionados à capacidade do sistema permitir o acesso equitativo à informação } \\
\text { (acessibilidade) no âmbito do público-alvo estabelecido em um projeto com } \\
\text { facilidades inerentes ao uso da interface (usabilidade). }\end{array}$ \\
\hline Intencionalidade & $\begin{array}{l}\text { A teoria da Intencionalidade fundamenta a importância em se enfatizar as } \\
\text { experiências e habilidades dos sujeitos informacionais no projeto de ambientes e } \\
\text { sistemas de informação. }\end{array}$ \\
\hline $\begin{array}{l}\text { Mobilidade, } \\
\text { Convergência e } \\
\text { Ubiquidade }\end{array}$ & $\begin{array}{l}\text { Estão associados ao meio ambiente, externo aos sistemas e ambientes } \\
\text { informacionais, mas que os incluem, dinamizando-os e potencializando as } \\
\text { possibilidades dos sujeitos em encontrar a informação por meio de diferentes } \\
\text { dispositivos e em diferentes contextos e situações. }\end{array}$ \\
\hline
\end{tabular}




\begin{tabular}{|c|l|}
\hline Atributo & \multicolumn{1}{|c|}{ Descrição } \\
\hline Responsividade & Capacidade de adaptação ao contexto de mobilidade, dispositivo ou ambiente. \\
\hline Consistência & $\begin{array}{l}\text { Capacidade de atender as finalidades, os contextos e as pessoas para as quais é } \\
\text { projetado na ecologia informacional complexa. }\end{array}$ \\
\hline Place -making & $\begin{array}{l}\text { Capacidade de redução da desorientação, de construção do sentido de } \\
\text { localização na ecologia informacional complexa. }\end{array}$ \\
\hline Redução & $\begin{array}{l}\text { Capacidade de gerenciar grandes conjuntos de informações e minimizar o estresse } \\
\text { efrustração associada com a escolha de um conjunto cada vez maior de fontes de } \\
\text { informação, serviços e produtos. }\end{array}$ \\
\hline Pervasividade & $\begin{array}{l}\text { Capacidade de sugerir conexões relevantes entre elementos de informação, } \\
\text { serviços e bens para ajudar os sujeitos informacionais a alcançar objetivos } \\
\text { explicitados ou estimular necessidades latentes. }\end{array}$ \\
\hline $\begin{array}{l}\text { Capacidade ou tendência de mover-se, propagar-se, infiltrar-se, difundir-se total } \\
\text { ou inteiramente através de vários meios, canais, sistemas, tecnologias, etc. }\end{array}$ \\
\hline
\end{tabular}

Fonte: Vechiato, Oliveira e Vidotti (2016)

Esses atributos permitem com que as informações sejam encontradas pelos seus usuários, ou seja, pelos sujeitos de uma determinada ecologia informacional. O modelo de Encontrabilidade da Informação e Arquitetura da Informação Pervasiva proposto pelos autores supracitados considera esta realidade atual na busca de informações em ecologias informacionais complexas (BRANDT; VECHIATTO; VIDOTTI, 2018).

Apropriando-nos da Encontrabilidade da Informação no contexto dos ambientes informacionais digitais vemos essa nova abordagem como um sustento para a recuperação da informação. O processo de encontrabilidade não é distanciado da Arquitetura da Informação, uma vez que ele vai além da interface.

Vechiato (2013) comenta que a "expressão 'ambient findability' que empresta o título ao livro de Morville (2005) alia a internet e a computação ubíqua". Nesse sentido, Oliveira (2014) destaca a informação pervasiva, como aquela que está presente em todos os lugares e diversas formas e acesso. Nesse ínterim a Arquitetura da Informação Pervasiva pode ser entendida como:

[...] uma abordagem teórico-prática da disciplina científica pós-moderna Arquitetura da Informação, trata da pesquisa científica e do projeto de ecologias informacionais complexas. Busca manter o senso de localização do usuário na ecologia e o uso de espaços, ambientes e tecnologias de forma convergente e consistente. Promove a adaptação da ecologia à usuários e aos novos contextos, sugerindo conexões no interior da ecologia e com outras ecologias. Facilita a interação com conjuntos de dados e informações ao considerar os padrões interoperáveis a acessibilidade, a usabilidade, as qualidades semânticas e a encontrabilidade da informação, portanto deve buscar bases na Ciência da Informação. (OLIVEIRA, 2014, p. 166). 
As discussões teóricas da Arquitetura da Informação Pervasiva e da Encontrabilidade da Informação, se relacionam permitindo novos desdobramentos e estudos nos ambientes informacionais híbridos por meio da intersecção da disciplina científica Arquitetura da Informação. (VECHIATO; OLIVEIRA; VIDOTTI, 2016)

Assim, apropriando-nos desses atributos no contexto dessa pesquisa consideramos essa nova abordagem para além da navegação, interface e da busca em sistemas e ambientes, e destacamos os aspectos que delineiam as características dos sujeitos informacionais, aliados com a mobilidade, convergência e ubiquidade provenientes do desenvolvimento tecnológico.

\section{Encontrabilidade da informação em ambientes informacionais LGBTQ}

O olhar social da Informação no contexto da Web destaca um dos principais desafios da Ciência da Informação "transformar a massa de dados operacionais disponíveis diariamente em informações consistentes que permitam a tomada de decisões e agreguem valor às atividades" (SANTOS; VIDOTTI, 2009, p. 7).

As necessidades dos usuários da comunidade LGBTQ, a diversidade de linguagens informacionais, e o tempo de aprendizagem dos sujeitos como um contínuo são características fundamentais que devem ser observadas no desenvolvimento de ambientes informacionais digitais. (OLIVEIRA, 2014). No contexto da Encontrabilidade da Informação, a folksonomia possibilita que os sujeitos informacionais insiram e apresentem os termos de acordo com as suas necessidades informacionais e os seus conhecimentos prévios.

Para Vechiato e Vidotti (2014), no âmbito da 'Encontrabilidade da Informação', as folksonomias estão relacionadas à organização social da informação e propiciam ao sujeito à classificação de recursos informacionais, a localização da informação por meio da navegação ou pelo sistema de busca.

Segundo Assis e Moura (2013), a folksonomia proporciona um processo que potencializa o uso dos ambientes informacionais digitais, tanto na organização como no compartilhamento dos recursos informacionais.

A comunidade LGBTQ apresenta uma diversidade linguística específica de sua comunidade (GUIMARÃES et al., 2017; CAMPBELL et al., 2017) e os ambientes informacionais digitais devem estar adequados às necessidades, às competências e aos comportamentos informacionais desses usuários, para que o público venha construir conhecimento a partir das informações encontradas no ambiente web.

Essa diversidade linguística particularizada pela comunidade LGBTQ é conhecida como Pajubá. O vocabulário Pajubá é um dialeto que configura um conjunto de palavras utilizadas 
inicialmente pelas travestis e atualmente por toda comunidade LGBTQ e possuem origens nos terreiros de matriz africana (COSTA NETO, 2006).

Nesse sentido, se discute a complexidade da linguagem na web caracterizada pelo hibridismo de manifestações sígnicas e de símbolos, porém, com o predomínio do simbólico, sendo, dessa forma, o palco de acordos interpretativos que se determinam e se transformam por hábitos e convenções estabelecidas entre os sujeitos informacionais (ASSIS; MOURA, 2013).

As manifestações sígnicas representam fortemente o vocabulário da comunidade LGBTQ, sendo desenhadas pelo sistema de rótulos a que são atribuídos. Esses rótulos são embutidos, geralmente, nas taxonomias navegacionais.

Sob essa perspectiva e se apropriando das ideias de Oliveira (2014) e amalgamando com as ideias de Foucault (1999) pensar em ambientes informacionais que envolvam questões de gênero é pensar além dos processos cognitivos e conhecendo do usuário.

Foucault (1999, p. 89) comenta ainda que "[...] a sexualidade não é um fenômeno biológico somente (o corpo reinando soberano a partir da presença ou ausência da genitália), ela é social e histórica". Sendo assim, a sexualidade retratada em ambiente web sinaliza essas expressões de manifestações sociais.

Por meio dessa complexidade, Camargo (2010) explica que a interface é o intermediário entre os usuários e conteúdo, um intérprete e guia das complexidades de um website. No ambiente da web o projeto da interface tem que lidar com o significado da estrutura visual (sistemas de rotulagem) para possibilitar uma navegação clara e específica para o público que se pretende atender (BRITO AFONSO, MATIAS, 2019)

Um dos requisitos essenciais para o projeto de ambientes informacionais digitais, segundo Badre (2002) e Vechiato (2010) é a definição do público-alvo. Para os autores, o perfil dos usuários influencia sobremaneira o design e a avaliação da interface. Nesse sentido, é necessário considerar as diversidades humanas relacionadas aos sujeitos informacionais envolvidos.

Brito, Silva e Matias (2017, p 28) comentam que observou-se o crescimento do acesso aos websites que discutem gênero e sexualidade por públicos diferenciados, o que corrobora para a inserção da comunidade LGBTQ nas atividades de disseminação, apropriação e uso da informação mostrando as dimensões abrangentes que esse público atingiu nos últimos anos. Com isso quanto maior o público e o conteúdo informacional que se pretende abranger, mais coerência e padrão o sistema deve oferecer, pensando como o usuário irá interagir.

\section{5 o Museu da Diversidade Sexual enquanto ecologia informacional complexa}


O Museu da Diversidade Sexual é considerado uma ecologia informacional complexa, pois consiste em características que permeiam seus ambientes informacionais analógico e digital. Vechiato, Oliveira e Vidotti (2016, p. 97, grifo nosso) explicam que:

As Ecologias Informacionais Complexas são como um conjunto de espaços e ambientes, (analógicos, digitais ou híbridos), tecnologias (analógicas, digitais ou híbridas) e sujeitos, todos interligados e entrelaçados de maneira holística pela informação.

O MDS foi criado em 2012, pela Secretaria da Cultura do Estado de São Paulo, suas exposições têm como foco as atividades culturais, educativas que remetem as identidades de gênero, orientação sexual e expressão de gênero. As exposições são compostas por imagens, fotos, objetos e vídeos, feitos por pessoas LGBTQ, que encontram dificuldade de expor sua arte em outros locais. (MUSEU DA DIVERSIDADE SEXUAL, 2019).

Na figura 1 apresenta-se a Entrada Principal do Museu da Diversidade Sexual situado no térreo da Estação República do Metrô de SP.

Figura 1: Entrada do Museu da Diversidade Sexual

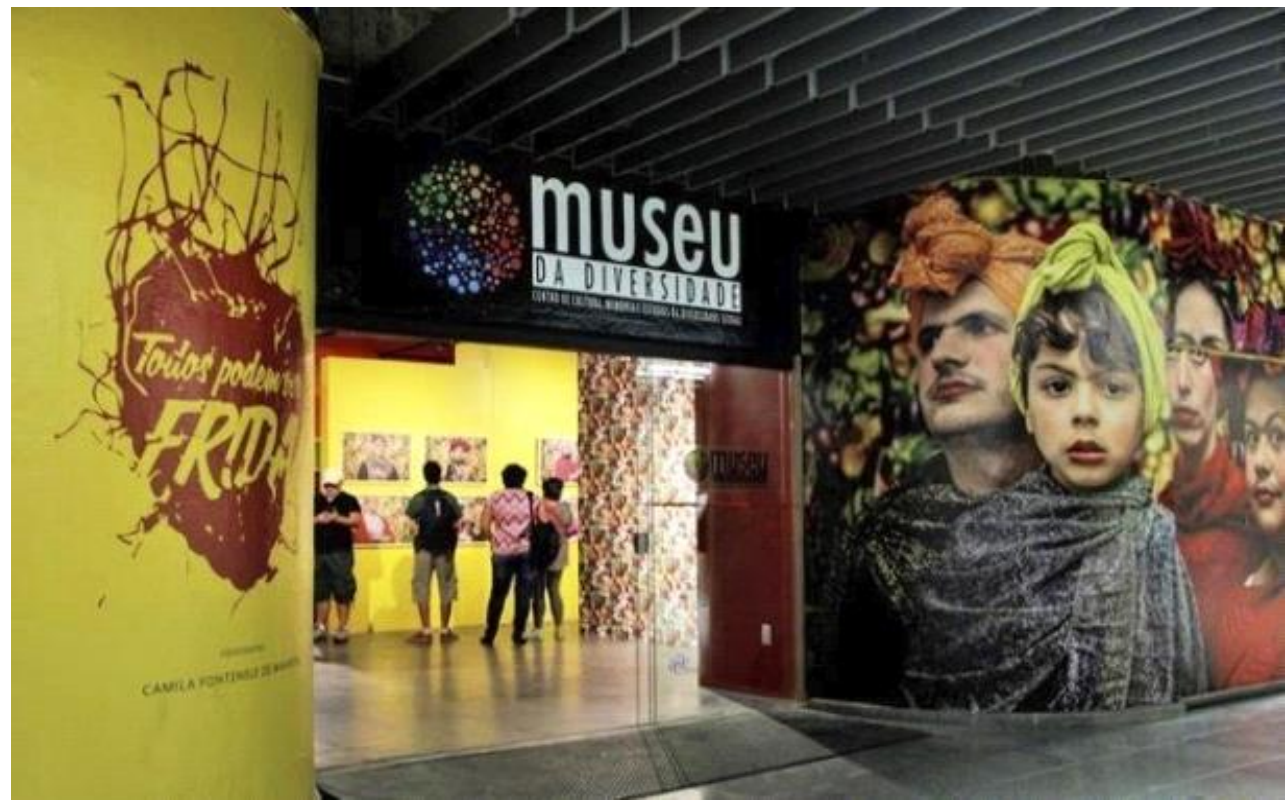

Fonte: revistaviag.com.br

Na figura 2 apresenta-se o printscreen da Página Principal do Museu da Diversidade Sexual, retratando especificamente o dia internacional de combate a LGBTFOBIA.

Figura 2: Página principal do website do Museu da Diversidade Sexual 


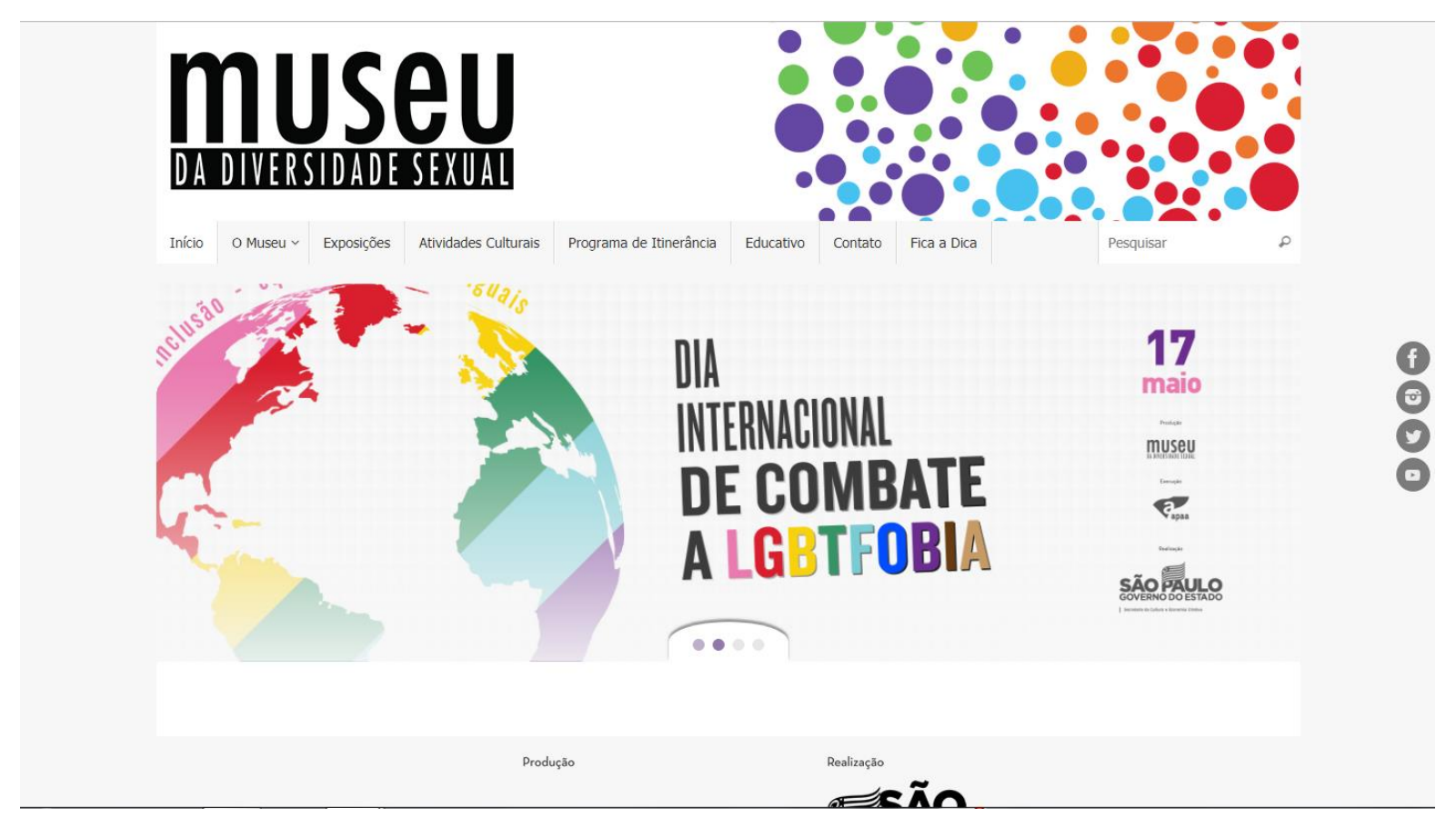

Fonte: mds.org.br. Acesso em: 12 maio. 2019

Com exposições itinerantes o seu acervo está localizado no Metrô República. É uma Organização Social que apresenta vínculo com a Assessoria de Cultura para Gêneros e Etnias da Secretaria da Cultura de São Paulo. Foi criado com o objetivo de preservar o patrimônio sócio, político e cultural da comunidade LGBT do Brasil. Apresenta referências materiais e imateriais sobre a trajetória LGBTQ.

\section{Aspectos metodológicos}

Como foi apresentado anteriormente o MDS foi avaliado com base no instrumento proposto por Vechiato, Oliveira e Vidotti (2016). A avaliação foi dividida em duas etapas. A primeira foi realizada a partir da análise do website do MDS e a sua segunda etapa foi no ambiente analógico por meio de uma visita a instituição, utilizando-se da técnica de observação participante. A coleta de dados foi realizada no mês de maio de 2018 durante uma exposição sobre a Parada do Orgulho LGBTQ.

O instrumento de análise foi elaborado a partir dos atributos da Encontrabilidade da Informação e sua relação com os atributos da Arquitetura da Informação Pervasiva e tem por objetivo colaborar com-o projeto e a avaliação de ecologias informacionais híbridas (VECHIATO; OLIVEIRA; VIDOTTI, 2016).

Para o desenvolvimento da reflexão teórica sobre os ambientes informacionais LGBTQ, ajuizamos utilizar a pesquisa bibliográfica em bases de dados. De acordo com Prodanov e Freitas 
(2003, p. 54), a pesquisa bibliográfica tem o objetivo "[...] de colocar o pesquisador em contato direto com todo material já escrito sobre o assunto da pesquisa."

\section{Resultados e discussões}

No quadro 2, apresenta-se o resultado da avaliação da ecologia informacional complexa do MDS.

Quadro 2: Avaliação da Encontrabilidade da Informação no MDS

\begin{tabular}{|c|c|c|c|}
\hline Atributo & Checklist & $\begin{array}{l}\text { S-Sim } \\
\text { N-Não } \\
\text { P-Parcial } \\
\text { NA- Não } \\
\text { Aplicável }\end{array}$ & Observação \\
\hline \multirow[b]{2}{*}{$\begin{array}{l}\text { Taxonomias } \\
\text { navegacionais }\end{array}$} & $\begin{array}{l}\text { A taxonomia navegacional existente } \\
\text { possui categorização adequada dos } \\
\text { conceitos/termos. }\end{array}$ & $P$ & $\begin{array}{l}\text { As taxonomias } \\
\text { navegacionais apresentam } \\
\text { termos não muito } \\
\text { significantes à comunidade }\end{array}$ \\
\hline & $\begin{array}{l}\text { A taxonomia navegacional existente } \\
\text { possui termos significativos e coerentes } \\
\text { que não dificultam seu entendimento }\end{array}$ & $P$ & $\begin{array}{l}\text { Os termos utilizados nas } \\
\text { taxonomias navegacionais } \\
\text { são confusos e apresentam } \\
\text { ambiguidades ao usuário. }\end{array}$ \\
\hline $\begin{array}{l}\text { Instrumentos de } \\
\text { controle } \\
\text { terminológico }\end{array}$ & $\begin{array}{l}\text { São utilizados vocabulários controlados, } \\
\text { tesauros e/ou ontologias para a } \\
\text { representação do assunto dos recursos } \\
\text { informacionais. }\end{array}$ & $\mathrm{N}$ & Não possui \\
\hline \multirow[t]{2}{*}{ Folksonomias } & $\begin{array}{l}\text { Há recursos de classificação social } \\
\text { (folksonomia) que favoreçam a } \\
\text { participação dos sujeitos } \\
\text { informacionais. }\end{array}$ & $N$ & Não possui \\
\hline & $\begin{array}{l}\text { As tags geradas pelos sujeitos são } \\
\text { disponibilizadas em nuvem de tags, } \\
\text { para facilitar a navegação social. }\end{array}$ & $N$ & Não possui \\
\hline \multirow[b]{2}{*}{ Metadados } & $\begin{array}{l}\text { Os recursos informacionais estão } \\
\text { representados por metadados. }\end{array}$ & $\mathrm{N}$ & Não possui \\
\hline & $\begin{array}{l}\text { É utilizado padrão de metadados } \\
\text { coerente com a proposta do ambiente } \\
\text { informacional. }\end{array}$ & $N$ & Não possui \\
\hline $\begin{array}{l}\text { Mediação dos } \\
\quad \text { sujeitos } \\
\text { institucionais } \\
\text { (informáticos e } \\
\text { profissionais da } \\
\text { informação) }\end{array}$ & $\begin{array}{l}\text { O ambiente disponibiliza formas de } \\
\text { auxílio aos sujeitos informacionais a } \\
\text { partir de tutoriais (ambientes digitais) } \\
\text { ou assistência presencial (ambientes } \\
\text { analógicos). }\end{array}$ & $P$ & $\begin{array}{l}\text { Apresenta apenas um fale } \\
\text { conosco. No ambiente } \\
\text { analógico o usuário tem a } \\
\text { possibilidade de visitas } \\
\text { guiadas ou agendar visitas } \\
\text { em grupo. }\end{array}$ \\
\hline \multirow{2}{*}{$\begin{array}{l}\text { Mediação dos } \\
\text { sujeitos } \\
\text { informacionais }\end{array}$} & $\begin{array}{l}\text { Os sujeitos participam da produção da } \\
\text { informação disponibilizada. }\end{array}$ & $\mathrm{N}$ & $\begin{array}{c}\text { Não há participação dos } \\
\text { sujeitos }\end{array}$ \\
\hline & $\begin{array}{l}\text { Os sujeitos participam da organização / } \\
\text { representação da informação } \\
\text { disponibilizada }\end{array}$ & $\mathrm{N}$ & $\begin{array}{c}\text { Não há participação na } \\
\text { organização da informação }\end{array}$ \\
\hline
\end{tabular}




\begin{tabular}{|c|c|c|c|}
\hline Affordances & $\begin{array}{l}\text { As affordances aplicadas facilitam o } \\
\text { entendimento por diferentes tipos de } \\
\text { sujeitos informacionais. }\end{array}$ & $\mathrm{P}$ & $\begin{array}{l}\text { Utiliza se affordances } \\
\text { pontuais e ligadas aos } \\
\text { rótulos das redes sociais, } \\
\text { quais sejam: Facebook, } \\
\text { Twitter e Instagram. }\end{array}$ \\
\hline Wayfinding & $\begin{array}{l}\text { O ambiente utiliza marcos e/ou } \\
\text { metáforas que dão pistas ao sujeito } \\
\text { para orientá-lo no espaço digital e/ou } \\
\text { analógico. }\end{array}$ & $P$ & $\begin{array}{l}\text { No analógico, utiliza placas e } \\
\text { legendas sobre as } \\
\text { exposições. }\end{array}$ \\
\hline \multirow{4}{*}{$\begin{array}{l}\text { Descoberta de } \\
\text { informações }\end{array}$} & $\begin{array}{l}\text { O mecanismo de busca utiliza o recurso } \\
\text { autocomplete ou autossugestão }\end{array}$ & $\mathrm{N}$ & Não possui \\
\hline & $\begin{array}{l}\text { Na página com os resultados de busca } \\
\text { são apresentadas facetas para o } \\
\text { refinamento da pesquisa. }\end{array}$ & $\mathrm{N}$ & Não possui \\
\hline & $\begin{array}{l}\text { Os resultados de busca apresentam } \\
\text { diversos tipos de documentos com base } \\
\text { na estratégia de busca inicial do sujeito, } \\
\text { apresentando-os de forma relacionada. }\end{array}$ & $\mathrm{N}$ & Não possui \\
\hline & $\begin{array}{l}\text { Há informações utilitárias nos espaços } \\
\text { analógicos. }\end{array}$ & $P$ & $\begin{array}{c}\text { Há pequenos blocos de } \\
\text { informações no início de } \\
\text { museu. }\end{array}$ \\
\hline \multirow{4}{*}{$\begin{array}{l}\text { Acessibilidade e } \\
\text { Usabilidade }\end{array}$} & O ambiente possui usabilidade. & $\mathrm{P}$ & $\begin{array}{c}\text { Apresenta uma interface } \\
\text { simples que reforçam as } \\
\text { cores da comunidade } \\
\text { LGBTQ }\end{array}$ \\
\hline & $\begin{array}{l}\text { O ambiente digital possui recursos de } \\
\text { acessibilidade digital na interface. }\end{array}$ & $\mathrm{N}$ & Não apresenta \\
\hline & $\begin{array}{l}\text { O ambiente analógico possui recursos } \\
\text { de acessibilidade. }\end{array}$ & $\mathrm{S}$ & $\begin{array}{c}\text { Como o museu fica dentro } \\
\text { da estação do metrô } \\
\text { República, ele utiliza toda a } \\
\text { acessibilidade e } \\
\text { infraestrutura do Metrô SP } \\
\text { (Sanitários para deficientes, } \\
\text { piso táteis) }\end{array}$ \\
\hline & $\begin{array}{l}\text { Foram utilizadas as recomendações de } \\
\text { acessibilidade da W3C (WCAG 2.0). }\end{array}$ & $P$ & $\begin{array}{l}\text { De acordo com a validação } \\
\text { do sistema do website } \\
\text { apresentou o índice } 5.1\end{array}$ \\
\hline Intencionalidade & $\begin{array}{l}\text { Há indicativos de que a ecologia se } \\
\text { preocupa com a intencionalidade dos } \\
\text { sujeitos, por meio de tecnologias como } \\
\text { análise de log de interação ou outras. }\end{array}$ & $\mathrm{P}$ & $\begin{array}{l}\text { No analógico eles fazem } \\
\text { uma estatística por meio } \\
\text { das listas de presença. }\end{array}$ \\
\hline \multirow[t]{2}{*}{ Responsividade } & Possui interface responsiva. & $P$ & $\begin{array}{c}\text { Apresenta uma interface } \\
\text { responsiva, mas que carece } \\
\text { de estruturação, pois alguns } \\
\text { conteúdos somem da } \\
\text { página }\end{array}$ \\
\hline & $\begin{array}{l}\text { Permite a continuidade das ações dos } \\
\text { sujeitos informacionais entre os } \\
\text { diferentes dispositivos. }\end{array}$ & $\mathrm{N}$ & Não identifica o usuário \\
\hline Ubiquidade & $\begin{array}{l}\text { Há indicativos de que a ecologia possui } \\
\text { tecnologias ubíquas. }\end{array}$ & $\mathrm{N}$ & Não possui \\
\hline Consistência & $\begin{array}{l}\text { As distintas partes da ecologia } \\
\text { informacional possuem consistência } \\
\text { entre si. }\end{array}$ & $P$ & $\begin{array}{l}\text { Há partes da ecologia que } \\
\text { são consistentes como: } \\
\text { exposições e fale conosco }\end{array}$ \\
\hline
\end{tabular}




\begin{tabular}{|c|c|c|c|}
\hline \multirow{2}{*}{ Placemaking } & $\begin{array}{l}\text { Permite que os sujeitos informacionais } \\
\text { mantenham-se orientados, construindo } \\
\text { sentido de localização na ecologia } \\
\text { informacional complexa. }\end{array}$ & $P$ & $\begin{array}{l}\text { Não possui uma construção } \\
\text { de sentido dentro da } \\
\text { ecologia informacional. }\end{array}$ \\
\hline & $\begin{array}{l}\text { Atende finalidades, contextos e } \\
\text { comunidades específicas. }\end{array}$ & $P$ & $\begin{array}{l}\text { O ambiente atende } \\
\text { parcialmente membros da } \\
\text { comunidade LGBTQ e } \\
\text { também os simpatizantes }\end{array}$ \\
\hline \multirow{2}{*}{$\begin{array}{l}\text { Redução e } \\
\text { Resiliência }\end{array}$} & $\begin{array}{l}\text { Gerencia grandes conjuntos de } \\
\text { informações e minimiza o estresse e } \\
\text { frustração na escolha de fontes de } \\
\text { informação, serviços e produtos. }\end{array}$ & $P$ & $\begin{array}{c}\text { A busca não contempla todo } \\
\text { o conteúdo do website. Há } \\
\text { ambiguidades na } \\
\text { navegação. }\end{array}$ \\
\hline & $\begin{array}{l}\text { A ecologia ou partes da ecologia se } \\
\text { adapta à sujeitos informacionais } \\
\text { específicos, necessidades específicas e } \\
\text { estratégias de busca contextuais. }\end{array}$ & $\mathrm{S}$ & $\begin{array}{c}\text { Adapta as exposições da } \\
\text { comunidade LGBTQ, } \\
\text { atendendo principalmente } \\
\text { jovens e adultos. }\end{array}$ \\
\hline \multirow{2}{*}{ Correlação } & $\begin{array}{l}\text { Sugere conexões relevantes entre } \\
\text { elementos de informação, serviços e } \\
\text { bens. }\end{array}$ & $\mathrm{S}$ & $\begin{array}{c}\text { Há links e divulgação das } \\
\text { novas exposições no } \\
\text { website e no analógico }\end{array}$ \\
\hline & $\begin{array}{l}\text { Ajuda os sujeitos informacionais a } \\
\text { alcançar objetivos explicitados ou } \\
\text { estimular necessidades latentes. }\end{array}$ & $\mathrm{N}$ & Não possui \\
\hline \multirow{2}{*}{ Pervasividade } & $\begin{array}{l}\text { Possui estrutura ecológica com uma } \\
\text { diversidade de ambientes, meios, } \\
\text { canais, sistemas, tecnologias, etc. }\end{array}$ & $\mathrm{S}$ & $\begin{array}{l}\text { A ecologia está presente em } \\
\text { diversos canais de } \\
\text { comunicação, quais sejam, } \\
\text { redes sociais, websites, } \\
\text { folders. }\end{array}$ \\
\hline & $\begin{array}{l}\text { Permite a tendência de movimento, } \\
\text { propagação, infiltração, difusão total ou } \\
\text { parcial através de vários ambientes, } \\
\text { meios, canais, sistemas, tecnologias, } \\
\text { etc. }\end{array}$ & $\mathrm{S}$ & $\begin{array}{l}\text { A ecologia permite uma } \\
\text { propagação por meio de } \\
\text { diversos canais e } \\
\text { tecnologias. }\end{array}$ \\
\hline
\end{tabular}

Fonte: Dados da pesquisa, 2019.

De um modo geral, por se tratar de uma ecologia informacional complexa apresenta-se uma diversidade dos fatores envolvidos. O MDS apresentou em sua grande maioria uma parcialidade no que diz respeito aos atributos de Encontrabilidade da Informação e Arquitetura da Informação Pervasiva.

As taxonomias navegacionais, folksonomias, instrumentos de controles terminológicos são ausentes, o que dificultam uma maior participação dos usuários com termos e rótulos específicos.

O vocabulário Pajubá poderia estar incluído nos rótulos específicos no website principalmente para facilitar o processo de representação em espaços das exposições, quais sejam vídeos, quadros, murais e até mesmo na apresentação geral do MDS.

As Affordances e Wayfinding no ambiente digital apresentam-se como pontuais ligados às mídias sociais, enquanto que no analógico são representados por meio de placas e legendas sobre as exposições. Vale destacar que o espaço físico do museu se encontra dentro da estação 
do metrô República da cidade de São Paulo, e parte das sinalizações está relacionado com a rede da Companhia do Metropolitano de São Paulo.

O website apresenta mediação do sujeito institucional bem simples. O website ainda oferece canais de interação como o "Fale conosco", e-mails e telefones. No ambiente analógico, há apenas um balcão de recepção e atendimentos aos usuários. Em relação à mediação dos sujeitos informacionais, esta é inexistente: os usuários não participam nem da produção, e nem da organização dos conteúdos informacionais da ecologia.

No que diz respeito à usabilidade e acessibilidade o website apresenta uma interface simples com traços ligados a comunidade LGBTQ, quais sejam, as cores do arco íris, além disso, o ambiente digital não possui recursos de acessibilidade digital. No validador de acessibilidade, Access Monitor ${ }^{1}$, o website obteve nota 5.1 e uma de suas maiores incidências foi à falta de legendas nas imagens (exposições), o que dificulta o acesso pelo usuário cego ou com baixa visão. No analógico ele possui pisos táteis e elevador para cadeirantes, que fazem parte do Metrô República.

Sobre a intencionalidade dos sujeitos, eles apresentam listas de presenças e geram estatísticas sobre as visitas no museu. A presença de heterossexuais é alta no museu, apresentando termos e rótulos gerais.

Sobre os atributos Placemaking e Redução e Resiliência o ambiente atende maioritariamente os membros da comunidade LGBTQ e simpatizantes, no entanto a busca não contempla todo o conteúdo no website, pois apresenta ambiguidades na navegação.

A correlação é apresentada parcialmente por meio de links e pela divulgação das novas exposições no website e no ambiente analógico. Estende-se também a outros websites do governo do estado e da cidade de São Paulo, como a Associação Brasileira de Turismo LGBTQ (ABTLGBT) que contribui para a visibilidade do MDS.

Nesta ecologia, consideram-se os atributos de pervasividade e correlação bastante completa. Tanto o analógico quanto o digital apresentam uma estrutura tecnológica e a sua divulgação e propagação se dá por diversos meios e canais, seja por redes sociais (Twitter, Facebook e Instagram) e panfletos espalhados pelos pontos de informações turísticas da cidade. Não há indicativos de tecnologias ubíquas.

Percebemos que os maiores problemas encontrados no website se referem às descobertas de informação e a mediação dos sujeitos informacionais, ausência de elementos de acessibilidade, os quais possibilitariam ampliar o acesso à informação por pessoas com

\footnotetext{
${ }^{1}$ Disponível em: http://www.acessibilidade.gov.pt/accessmonitor/ 
deficiência. A folksonomia utilizando as Hashtags é um atributo que poderia ser modificada e embutida no website ao se tratar das mídias sociais apresentadas pelo MDS.

Com base na análise no MDS, a partir dos pressupostos teóricos da Encontrabilidade da Informação e da Arquitetura da Informação Pervasiva, destaca-se pontos relevantes que podem interferir no processo de uso e disseminação da informação de forma favorável e desfavorável, sintetizados no Quadro 3, a seguir.

Quadro 3: Síntese dos aspectos positivos e pontos de melhoria identificados na ecologia informacional do MDS

\begin{tabular}{|c|c|}
\hline Pontos positivos & Pontos a melhorar \\
\hline $\begin{array}{l}\text { - Possui recursos de acessibilidade no espaço. } \\
\text { Utiliza toda a acessibilidade e infraestrutura do } \\
\text { Metro SP (Sanitários para deficientes, piso } \\
\text { táteis). } \\
\text { - A ecologia está presente em diversos canais de } \\
\text { comunicação, quais sejam redes sociais, } \\
\text { websites, folders. }\end{array}$ & $\begin{array}{l}\text { - As taxonomias navegacionais são confusas e } \\
\text { apresentam ambiguidades ao usuário. } \\
\text { - Há ausência de folksonomia e participação dos } \\
\text { usuários tanto no ambiente analógico quanto no } \\
\text { digital. }\end{array}$ \\
\hline $\begin{array}{l}\text { - Há links e divulgação das novas exposições no } \\
\text { website e no analógico. }\end{array}$ & $\begin{array}{l}\text { - O sistema de busca não contempla todo o } \\
\text { conteúdo do website, apresentando ambiguidades } \\
\text { na navegação; }\end{array}$ \\
\hline $\begin{array}{l}\text { - A ecologia permite uma propagação por meio } \\
\text { de diversos canais e tecnologias }\end{array}$ & \\
\hline
\end{tabular}

Fonte: Autoria própria, 2020.

A análise e discussão dos resultados anteriormente apresentados permitiram identificar uma síntese dos aspectos positivos e negativos na ecologia informacional estudada. A análise no website e a observação participante no museu possibilitaram a compreensão do MDS e as interações nos recortes analisados nas atividades comunicacionais com os usuários, bem como uma melhor compreensão sobre os atributos de Encontrabilidade e Arquitetura da Informação Pervasiva.

\section{Considerações finais}

A Ciência da Informação a partir de seu caráter interdisciplinar apresenta as TIC como uma forma de viabilizar a estruturação de espaços informacionais digitais. A transação dos usuários pela diversidade de espaços informacionais, digitais ou não, lança desafios aos postulados pelo desenvolvimento tecnológico. 
Na avaliação do MDS o contexto se insere na disseminação de informação por meio de recursos audiovisuais divulgados por canais de comunicação como redes sociais, plataforma de vídeo, aplicativo móvel, eventos em diferentes lugares para diferentes públicos, percebendo que a informação se torna pervasiva por percorrer diferentes ambientes da organização.

Se atendido alguns dos atributos que estão ausentes, o MDS poderia potencializar as divulgações de ideias considerando os sujeitos informacionais no processo de produção e organização tornando o ambiente mais colaborativo e interativo e isso demonstra a importância de se aplicar e aprofundar estudos de Encontrabilidade da informação e de Arquitetura da Informação Pervasiva no âmbito das Ecologias Informacionais complexas.

\section{Referências}

ALYSON PUBLICATIONS. The Alyson almanac. Boston: Alyson Publications, 1989.

ASSIS, J. de; MOURA, M. A. Folksonomia: a linguagem das tags. Encontros bibli: revista eletrônica de biblioteconomia e ciência da informação, v. 18, n. 36, p. 85-106, jan./abr. 2013. Disponível em: https://periodicos.ufsc.br/index.php/eb/article/view/15182924.2013v18n36p85/24523. Acesso em: 26 mar. 2019.

BADRE, A. N. Shaping web usability: interaction design in context. Boston: Pearson Education, 2002.

BRANDT, M.; VECHIATO, F. L.; VIDOTTI, S.A.B.G. Encontrabilidade da Informação na Câmara dos Deputados. Em Questão, v. 24, n. 1, jan./abr. 2018. Disponível em: http://seer.ufrgs.br/index.php/EmQuestao/article/view/71734/43507. Acesso em: 12 jun. 2018.

BRITO, J.; AFONSO, R.; MATIAS, M. Arquitetura Da Informação Com Enfoque Semiótico No Guia Gay São Paulo. Brazilian Journal of Information Science: research trends, v. 13, n. 1, p. 68-76, 29 mar. 2019.

BRITO, J. F.; MATIAS, M. O Museu da Diversidade Sexual sob a ótica da Encontrabilidade da Informação. In: ENCONTRO NACIONAL DE PESQUISA EM CIÊNCIA DA INFORMAÇÃO (ENANCIB), 19., 2018, Londrina. Anais... XIX Encontro Nacional de Pesquisa em Ciência da Informação, 2018.

BRITO, J. F.; SILVA, R. C; MATIAS, M. Arquitetura da Informação e Sintaxe das linguagens imagéticas no website Guia Gay Floripa. In: WORKSHOP DE INFORMAÇÃO, DADOS E TECNOLOGIA WIDAT, 1. Anais... v. 1, p. 28. 2017. Disponível em: http://www.periodicos.ufpb.br/ojs/index.php/itec/article/view/38112/21007. Acesso em: 26 mar. 2019

CAMARGO, L. S. A. de. Metodologia de desenvolvimento de ambientes informacionais digitais a partir dos princípios da arquitetura da informação. 2010. Tese (Doutorado em Ciência da Informação) - Faculdade de Filosofia e Ciências, Universidade Estadual Paulista. 2010.

CAMPBELL, D. Grant; et al. The Terminological Polyhedron in LGBTQ Terminology: self-naming as a power to empower in Knowledge Organization. Knowledge Organization, v. 44, n. 8, p. 586-591, 2017. 
COSTA NETO, A.G. A Linguagem no Candomblé: um estudo linguístico sobre as comunidade religiosas afro-brasileiras, 2006.

DE LA TIERRA, T. Latina lesbian subject headings: the power of naming. In: ROBERTO, K. R. Radical Cataloging: Essays at the Front. Jefferson: McFarland, 2008. p. 94-102.

FERREIRA, A. F.J.F.C.; VIDOTTI, S.A.B. Encontrabilidade da Informação em websites de Museus. Informação e Profissões. v. 5, n. 2, 2016. Disponível em: http://www.uel.br/revistas/uel/index.php/infoprof/article/view/26774/20510. Acesso em; 12 jun. 2018

FOUCAULT, M. História da sexualidade 1: a vontade de saber. Rio de Janeiro: Graal, 1999.

GREENBLATT, E. Homosexuality: The Evolution of a Concept in the Library of Congress Subject Headings. In: GOUGH, C.; GREENBLATT, E. Gay and Lesbian Library Service. Jefferson North Carolina: McFarland, 1990, p. 75-85.

GREENBLATT, E. The Treatment of LGBTIQ Concepts in the Library of Congress Subject Headings. In: GREENBLATT, E. Serving LGBTIQ Library and Archives Users: Essays on Outreach, Service, Collections and Access. McFarland, 2011, p. 212-228.

GUIMARÃES, J.A. C. et al. Knowledge Organization and the Power to Name: LGBTQ Terminology and the Polyhedron of Empowerment. NASKO, v. 6, n. 1, p. 67-73, 2017. Disponível em: https://journals.lib.washington.edu/index.php/nasko/article/view/15231 Acesso em; 26 mar. 2019.

MUSEU DA DIVERSIDADE SEXUAL. Sobre o museu. Disponível em: http://www.mds.org.br/quemsomos/ Acesso em: 12 maio. 2019

NUNAN, A. Homossexualidade: do preconceito aos padrões de consumo. Rio de Janeiro: Caravansarai Editora, 2003.

OLIVEIRA, H. P. C. de. Arquitetura da informação pervasiva: contribuições conceituais. 2014. 202 f. Tese (Doutorado em Ciência da Informação) - Universidade Estadual Paulista, Faculdade de Filosofia e Ciências de Marília, 2014. Disponível em: <http://hdl.handle.net/11449/110387>. Acesso em: 13 maio 2019.

OTTONICAR, S.L.C et al. Competência em informação no âmbito da comunidade LGBTQ: um levantamento das publicações científicas nacionais e internacionais. Informação \& Informação, Londrina, v. 24, n. 1, p. 484-512, mar. 2019. ISSN 1981-8920. Disponível em: <http://www.uel.br/revistas/uel/index.php/informacao/article/view/34561>. Acesso em: 23 maio 2019.

PINTO, R. Museu e Diversidade Sexual: reflexões sobre mostra LGBT e Queer. Revista de Arqueologia Pública, v.5, n. 1, 2012. Disponível em: https://periodicos.sbu.unicamp.br/ojs/index.php/rap/article/view/8635750/3467 Acesso em: 12.jun. 2018

POMPEU, S. L. E.; SOUZA, E. M. de. A produção científica sobre sexualidade nos estudos organizacionais: uma análise das publicações realizadas entre 2005 e 2014. Organ. Soc., Salvador, v. 25, n. 84, p. 50-67, Mar. 2018 . Disponível em: 
http://www.scielo.br/scielo.php?script=sci_arttext\&pid=S1984-

92302018000100050\&lng=en\&nrm=iso .Acesso em: 23 maio 2019.

PRODANOV, C. C.; FREITAS, E. C. de. Metodologia do trabalho científico: métodos e técnicas da pesquisa e do trabalho acadêmico. 2. ed. Novo Hamburgo: Feevale, 2003. Disponível em: http://docente.ifrn.edu.br/valcinetemacedo/disciplinas/metodologia-do-trabalho-

cientifico/HYPERLINK "http://docente.ifrn.edu.br/valcinetemacedo/disciplinas/metodologiado-trabalho-\%20cientifico/e-book-mtc"e-book-mtc . Acesso em: 20 maio. 2019

SANTOS, P. L. V. A. C.; VIDOTI, S. A. B. G. Perspectivismo e tecnologias de informação e comunicação: acréscimos à ciência da Informação? Data Grama Zero, v. 10, n. 3, jun. 2009.

VECHIATO, Fernando Luiz; OLIVEIRA, Henry Poncio Cruz de; VIDOTTI, Silvana Aparecida Borsetti Gregorio. Arquitetura da informação pervasiva e encontrabilidade da informação: instrumento para a avaliação de ambientes informacionais híbridos. In: ENCONTRO NACIONAL DE PESQUISA EM CIÊNCIA DA INFORMAÇÃO, 17., 2016, Salvador. Anais... Salvador: PPGCI, UFBA, 2016. p. 37553773.

http://www.ufpb.br/evento/index.php/enancib2016/enancib2016/paper/view/4118/2571

Acesso em: 26 mar. 2019.

VECHIATO, F. L. Repositório digital como ambiente de inclusão digital e social para usuários idosos. 2010. 183f. Dissertação (Mestrado em Ciência da Informação) - Faculdade de Filosofia e Ciências, Universidade Estadual Paulista, Marília. 2010.

VECHIATO, F.L. Encontrabilidade da informação: contributo para uma conceituação no campo da Ciência da Informação. 2013. 206 f. Tese (Doutorado em Ciência da Informação) - Faculdade de Filosofia e Ciências de Marília. Universidade Estadual Paulista, 2013. Disponível em: https://www.marilia.unesp.br/Home/Pos-

Graduacao/CienciadaInformacao/Dissertacoes/Tese_de_Doutorado_-

_Fernando_Luiz_Vechiato.pdf Acesso em: 26 mar. 2019.

VECHIATO, F.L.; VIDOTTI, S.A.B.G.. Encontrabilidade da informação. São Paulo: Cultura Acadêmica, 2014. 204 p. (Coleção PROPG Digital-UNESP). 